\title{
Agente de viagens ou consultor de viagens? O perfil profissional da Agência Viajar Faz Bem de Campo Mourão (Paraná/PR, Brasil) para atuação com consultoria de viagens
}

\section{Travel agent or travel consultant? The professional profile of the Viajar Faz Bem Agency of Campo Mourão (Paraná/PR, Brazil) for travel advice acting}

\author{
Anna Caroline dos Santos Oliveira (OLIVEIRA, A. C. dos S.) \\ Carla Caroline Holm (HOLM, C. C.) ${ }^{* *}$
}

\begin{abstract}
RESUMO - A globalização e a evolução tecnológica promovem mudanças nos mais diversos setores do mundo o tempo todo e para poder acompanhar tais transformações, a atividade turística precisou se reinventar para que deste modo pudesse se manter em um mercado de alta competitividade. Estes processos deram origem ao consultor de viagens atuando no agenciamento, porém existem algumas divergências em relação à prestação de serviço destes profissionais quando comparada aos dos agentes de viagens e diante disso, nesse trabalho se discutiu acerca de qual seria o perfil deste profissional e quais os diferenciais necessários para a sua atuação no mercado. $\mathrm{O}$ objetivo geral consistiu em verificar a possibilidade de atuação no segmento de consultoria de viagens pela Agência Viajar Faz Bem de Campo Mourão (Paraná/PR, Brasil) e por meio de revisão bibliográfica, observação de campo e entrevistas com a equipe do empreendimento, o estudo de caso revelou que o consultor de viagens estaria primeiramente preocupado com a segurança, satisfação e atendimento personalizado do cliente final, de modo que este poderia ser um mercado mais explorado pela agência de viagens abordada no presente trabalho.
\end{abstract}

Palavras-chave: Turismo; Agente de Viagens; Consultor de Viagens.

ABSTRACT - Globalization and technological evolution promote changes in the most diverse sectors of the world all the time and in order to be able to follow these transformations, the tourist activity had to reinvent itself so that it could maintain itself in a market of high competitiveness. These processes gave rise to the travel consultant acting in the agency, but there are some divergences in relation to the service rendering of these professionals when compared to those of the travel agents and before that, in that work was discussed about what would be the profile of this professional and which necessary for their market performance. The general objective was to verify the possibility of working in the travel consultancy segment of the Viajar Faz Bem travel agency in Campo Mourão (Paraná/PR, Brazil) and through a bibliographical review, field observation and interviews with the project team, the study of case revealed that the travel consultant would be primarily concerned with the security, satisfaction and

\footnotetext{
* Formação: Bacharel em Turismo e Meio Ambiente pela Universidade Estadual do Paraná (UNESPAR). Atividade profissional: Microempreendedora da Anna Brigadeiros ME. Endereço físico para correspondência: Rua Harrison José Borges, 303. CEP: 87.300.380 - Campo Mourão - Paraná/PR Brasil. E-mail: oliveiraanna@icloud.com.

** Formação: Bacharel em Turismo; Mestrado em Desenvolvimento Comunitário; e Doutoranda em Geografia pela Universidade Estadual do Centro-Oeste (UNICENTRO). Endereço físico para correspondência: Rua Tibagi, 306. CEP: 84500-000 - Irati - Paraná/PR - Brasil. E-mail: karol_holm@hotmail.com
} 
personalized service of the end customer, so that this could be a market more explored by the travel agency addressed in the present work.

Key words: Tourism; Travel Agente; Travel Consultant. 


\section{INTRODUÇÃO}

Entendendo que o turismo é interdisciplinar e assim se relaciona com as demais áreas, sua definição varia conforme o local em que é realizado e a ciência que o estudará; para Barretto (2003) a atividade turística não é um fenômeno recente e caracteriza-se por ser complexa e diversificada, com múltiplas possibilidades de análise e atuação nas localidades que desejam tê-la como uma alternativa social e econômica. A autora destaca que com a evolução dos meios de transporte e necessidades de deslocamento, surge em 1841 o agenciamento de viagens quando Thomas Cook (Inglaterra) e Henry Wells (Estados Unidos) iniciam suas atividades como organizadores de viagens.

Desde então o papel do agente mudou, sobretudo com a globalização e no que diz respeito ao acesso e repasse de informações relativas aos produtos e serviços do agenciamento de viagens e turismo. Mas como saber se a fonte é confiável e a compra terá garantias?

O agente se torna então responsável por pesquisar, filtrar e classificar as informações intermediando o contato entre clientes e fornecedores turísticos (DANTAS, 2008) e com objetivo de atender necessidades, expectativas e obrigatoriedades envolvidas na estruturação de uma viagem, o profissional passa a ser mais que um simples vendedor de produtos e/ou serviços do turismo, o profissional torna-se um consultor de viagens, pois busca entender o perfil do passageiro e identificar os produtos e serviços adequados para só então oferecê-lo ao cliente, prezando pela sua segurança, conforto e satisfação.

Cientes disso, o objetivo geral do trabalho foi verificar a possibilidade de atuação no segmento de consultoria de viagens pela Agência Viajar Faz Bem de Campo Mourão (Paraná/PR, Brasil) e teve como objetivos específicos: a) compreender o papel do agente de viagens no cenário globalizado; b) apresentar as características do consultor de viagens diante das mudanças no/do mundo; e c) analisar a prestação de serviços oferecida pela agência Viajar Faz Bem. Tais objetivos foram delimitados levando-se em conta que, com a globalização os consumidores podem acessar informações e comprar diretamente com fornecedores por meio da internet, porém, torna-se necessário verificar a qualidade dessas informações e daí a importância do 
profissional durante o processo de negociação e desfrute do(s) produto(s) e/ou serviço(s) adquirido(s).

\section{METODOLOGIA}

Entendendo a importância do agenciamento para a prática de turismo se faz necessário compreender como o profissional deve operar a fim de atender as necessidades e expectativas do cliente. Sendo assim, o presente trabalho, conforme mencionado anteriormente, buscou identificar os elementos necessários que caracterizariam um consultor, de modo que este seja diferenciado de um agente no mercado do agenciamento de viagens; tal discussão foi aplicada a uma agência de viagens e turismo da cidade de Campo Mourão (Paraná/PR, Brasil), buscando identificar a potencialidade do empreendimento em se destacar no segmento.

Sabendo disso, esta pesquisa foi de caráter qualitativo, porque auferiu informações e analisou evidências que a base numérica por si só não daria conta de explicar; e do tipo estudo de caso, porque debruçou-se sobre uma micro realidade com a finalidade de, a partir dela, poder compreender um fenômeno presente no mercado de viagens e turismo.

O desenvolvimento da pesquisa esteve dividido em dois grandes momentos, sendo o primeiro a revisão bibliográfica e o segundo a pesquisa empírica. Julgou-se que a revisão bibliográfica seria importante por permitir uma visão mais crítica em relação às temáticas centrais abordadas e como elas vêm sendo exploradas em demais cenários no Brasil e mundo; já a pesquisa de campo mostrou-se fundamental para compreender se a prática está em consonância com a teoria e se o objeto de pesquisa atende ao esperado, a saber, atuação no segmento de consultoria de viagens pela Agência Viajar Faz Bem.

As temáticas centrais estipuladas para a revisão bibliográfica e compreensão do fenômeno abordado foram turismo, agenciamento de viagens e consultoria de viagens e os autores que permitiram tal apreensão foram Tomelin (2001); Dantas (2008), De la Torre (2003), Marín (2004), Braga (2008), Staxhyn (2010), Menezes e Staxhyn (2011) e Packman (2014), apenas para exemplificar. 
A pesquisa empírica, por sua vez, consistiu na observação in loco e realização de entrevistas com a equipe de profissionais da referida agência. Durante as observações o olhar esteve atento para o cotidiano do empreendimento, perfil dos clientes atendidos, produtos e serviços oferecidos e comportamento dos colaboradores em relação à prestação do serviço que desenvolviam; já as entrevistas focaram na qualidade do atendimento, percepção sobre as exigências do mercado, segmento de atuação da agência, compreensão do papel do agente e o consultor, desejo em exercer consultoria no empreendimento e qualificação profissional para atender as exigências e necessidades da demanda turística.

A partir dessas estratégias propostas e executadas, a análise das informações apreendidas e evidências registradas se deu por emparelhamento teórico-prático de modo que pudesse ser percebido a existência (ou não) de relação entre teoria e prática, bem como a real potencialidade da agência em atuar no segmento de consultoria de viagens dentro do mercado turístico.

\section{COMPREENDENDO O CENÁRIO DO TURISMO E DO AGENCIAMENTO DE VIAGENS NO BRASIL}

Em 2003 a Organização Mundial do Turismo (OMT) tornou-se organismo especializado da Organização das Nações Unidas (ONU) e consolidou-se como a instituição de turismo com maior relevância internacional, este organismo gestor do turismo ao redor do mundo possui caráter governamental (DIAS, 2006) e compreende o turismo como sendo "um conjunto de atividades produtivas concebidas para atender fundamentalmente os visitantes." (PACKMAN, 2014, p. 18). Desta forma, o turismo envolve uma série de profissionais, empreendimentos e organismos para que seja promovido.

Sabendo da abrangência e importância desta atividade, no Brasil em 2003 é criado o Ministério do Turismo (MTUR) e assim assume-se nacionalmente o potencial do país para o desenvolvimento do turismo, uma vez que este possui importância econômica, política e social para a população (MTUR, 2017). A partir do turismo é possível mudar positivamente a realidade de um local, como exemplo com a inserção de 
pessoas no mercado de trabalho e movimentação da economia da localidade e entendese, portanto, que a atividade é um fenômeno social complexo e diversificado e não se mantém sozinho; sendo assim para o desenvolvimento do turismo há envolvimento de diversos agentes sociais e econômicos, dos quais podem ser listados como exemplo o destino, a comunidade local, o turista e os equipamentos do trade (BARRETTO, 2003).

Dias (2006, p. 87) aponta que "o turismo é uma atividade fundamentalmente dependente do fator humano, e consequentemente, é um importante gerador de postos de trabalhos"; e as áreas de atuação desses profissionais são múltiplas, tais como empresas de transportes, hotelaria, e o agenciamento, apenas para exemplificar. Este último mostra-se como um importante agente do mercado turístico, pois tem como função principal a organização e gestão dos deslocamentos turísticos, bem como, colaboração na divulgação dos destinos e localidades para clientes que desejam desfrutar de seus momentos de lazer em local distinto do seu local de residência e/ou trabalho.

Historicamente, o ano de 1841 foi um marco para a história do turismo (ACERENZA, 2002), pois a atividade passa a acontecer de forma organizada por meio de um profissional do agenciamento de viagens; de acordo com Braga (2008, p. 4) "quando se fala do primeiro agente de viagem profissional, os estudiosos do turismo consideram Thomas Cook (1808-1892) o empreendedor pioneiro da área.”, pois ele contribuiu para o aperfeiçoamento das agências e como consequência com o desenvolvimento do próprio do turismo (DANTAS, 2008). Cook colaborou não só para o aprimoramento das agências de viagens, mas também para o desenvolvimento do próprio turismo; ele desenvolveu inúmeros instrumentos que foram revolucionários para o sistema de agenciamento e que ainda são utilizados em agências do mundo, como é o caso dos vouchers ${ }^{1}$ turísticos, por exemplo.

No Brasil, no fim do século XIX as primeiras agências de viagens foram registradas oficialmente como prestadoras de serviços e eram utilizadas por brasileiros e portugueses residentes no país (TOMELIN, 2001); não é possível afirmar com precisão qual foi a primeira agência brasileira, já que a bibliografia referente ao histórico das agências de viagens é escassa (BRIDI, 2010), entretanto é possível afirmar que as primeiras agências de viagens que se têm registro de atuação no país são filiais de

\footnotetext{
${ }^{1}$ Cupom que garante aos turistas a prestação dos serviços de hospedagem e receptivo contratados, assim como assegura aos profissionais envolvidos o pagamento já executado (TOMELIN, 2001, p. 20).
} 
empresas estrangeiras, como a Exprinter (Expresso Internacional) e a Wagon-Lits (BRAGA, 2008). A partir de revisões bibliográficas considera-se que foi no ano de 1943 que passar a existir a Agência Geral de Turismo na cidade de São Paulo, sendo a primeira empresa brasileira que passou a exercer a atividade no país (BRIDI, 2010).

Desde então e até o início do século XXI as agências passaram por diversas influências e como alguns destaques têm-se o desenvolvimento da aviação comercial e legislação aeroportuária; o fortalecimento do turismo doméstico e internacional; e a crescente do mercado na economia mundial.

Especificamente no Brasil, nas duas últimas décadas as agências sofreram com a oscilação da economia e o desenvolvimento e surgimento de tecnologias (como sistemas de informações e comunicação), isto porque inicialmente as atividades desempenhadas pelo profissional da área durante este processo de estruturação da atividade restringia-se principalmente a comercialização de destinos turísticos já consolidados, por meio da reserva de hotéis, transporte e guiamento em atratividades do local; entretanto, com o passar dos anos, surgimento de novas tecnologias e avanço nos sistemas de transporte, por exemplo, o profissional precisou acompanhar as mudanças e inovar para se manter no mercado. O relativo atraso tecnológico do país e a fragilidade da economia turística nacional ainda são pontuais e determinantes no que diz respeito aos benefícios ou perdas advindos do turismo e, mais que isso, influenciam diretamente no delineamento do futuro das agências de viagens que precisam acompanhar este cenário globalizado para manterem-se competitivas (TOMELIN, 2001).

As agências de viagens são compreendidas como empresas que têm por finalidade a realização de viagens por meio da prestação de serviços, informando, organizando e tomando medidas necessárias para que uma ou mais pessoas possam viajar (BENI, 1998). Dias (2006, p. 149) aponta que segundo a segundo a OMT:

[...] as agências de viagem são empresas que vendem ao público uma grande variedade de serviços associados com o ato de viajar, tais como transporte (incluindo o aluguel de veículos), alojamento e os pacotes turísticos estabelecidos através de um contrato ou uma comissão.

Neste mesmo viés, o MTUR (2010) entende que as agências são responsáveis pela comercialização de produtos e serviços de interesse turístico e para atender o mercado estão divididas em operadoras de viagens e agências de viagens; sendo que a 
primeira atua no planejamento, organização e comercialização de produtos turísticos para as agências de viagens, enquanto a segunda intermedia a relação entre fornecedor e cliente final por meio da comercialização dos produtos turísticos oferecidos por estas operadoras.

De forma geral, entende-se que as agências realizam a comercialização de produtos e serviços turísticos, por meio da intermediação, com objetivo de organizá-los e promovê-los com qualidade satisfatória ao cliente, levando em consideração as necessidades, expectativas e obrigatoriedades envolvidas neste processo.

Segundo Tomelin (2001, p. 45): "O mercado de agências de viagens é dependente do setor de viagens e turismo" e dito isto, é possível afirmar que as agências de maneira geral exercem um importante papel para a atividade turística e para o turista, uma vez que por meio desta intermediação cliente final tem todas as informações relativas ao destino a ser visitado e/ou atividade a ser executada.

A atuação da agência pode colaborar para minimizar transtornos relacionados à eventualidades que podem ocorrer em dada viagem e a figura deste profissional pode facilitar tais resoluções; já para o destino receptor, a importância das agências diz respeito a apresentação e/ou divulgação do destino aos turistas, sendo importante ressaltar que as empresas podem fazer isto de forma benéfica ou não para determinado destino. Para a economia, por sua vez, as agências de viagens e turismo geram resultados positivos local e globalmente por meio da geração de empregos diretos e/ou indiretos e com a emissão ou recepção de turistas em determinado destino.

Assim exposto, entende-se que os agentes de viagens são profissionais com um importante papel nesses empreendimentos, uma vez que estão a frente da empresa informando e vendendo os produtos turísticos, e este atendimento determinará a qualidade na prestação de serviços oferecida pela agência (DANTAS, 2008).

\section{PERFIL DO PROFISSIONAL DO AGENCIAMENTO DE VIAGENS}

O agente de viagens desempenha a organização, promoção, reservas e vendas de serviços e produtos turísticos; bem como tem capacidade para facilitar o trâmite de documentos como passaporte, vistos, seguros, entre outros, e por meio disso o 
profissional do agenciamento atua ligando o produto turístico ao cliente para que todos os envolvidos obtenham ganhos no processo (DE LA TORRE, 2003). O profissional atuante tem papel de grande importância na empresa e é uma peça fundamental para o funcionamento da agência, pois além de ser o contato dos clientes, também é contato para todos os fornecedores, sejam eles meios de transporte, hospedagem, seguradoras, casas de câmbio ou despachantes, por exemplo. De acordo com Staxhyn (2010, p. 26), "os agentes de viagens, é que interagem com seus clientes, com fornecedores dos serviços turísticos, caracterizando um elo de confiabilidade para ambas as partes".

Ao adquirir bens e/ou serviços turísticos, o turista espera que suas necessidades ou que a motivação que o levou a aquisição destes produtos e/ou serviços seja atendida e para isto o empreendimento deve contar com uma equipe preparada para atender o consumidor (DIAS, 2006). Os serviços que compreendem a atividade turística na visão de Dantas (2008, p. 12) "são intangíveis, que não podem ser estocados ou transferidos fisicamente e devem ser consumidos no ato da oferta ou utilização [...]", deste modo, a agência de viagens e o profissional que nela atua têm como responsabilidade a prestação de serviço de qualidade e que atenda as expectativas daquele que irá viajar desde o momento da compra até o retorno desses passageiros.

Mediante o exposto, é possível afirmar que o agente precisa suprir as necessidades e expectativas do cliente e isso se mostra como um desafio, pois segundo Tomelin (2001, p. 15): “As aspirações, os sonhos, as necessidades, as opiniões e os desejos variam de uma pessoa para outra. [...] Os consumidores do turismo refletem a diversidade sociocultural da comunidade onde a agência está inserida.”. Entende-se então que o agente precisa identificar o que é melhor para cada cliente e criar o elo entre fornecedor e consumidor final da melhor maneira possível, pois este profissional trabalha com sonhos, expectativas e/ou necessidades de pessoas diferentes.

Cientes disso julga-se que são necessárias algumas características específicas para que a função seja desempenhada com sucesso, como por exemplo, a empatia, responsabilidade, agilidade, informações confiáveis e atualizadas, citadas tão somente como exemplos. Atesta-se que é preciso que haja qualificação, de modo que as informações passadas sejam corretas e atualizadas, bem como se consiga passar credibilidade ao cliente para que este adquira na agência os produtos e/ou serviços e não por outro meio. Assim, é possível afirmar que o profissional da área deve manter-se 
atento às transformações do mercado e de tudo que nele está implicado, pois estes fatores interferem diretamente no serviço prestado.

Nota-se, portanto, que a capacitação do agente de viagens é de muita importância, pois o profissional precisa ser sensível para entender a necessidade do cliente e também apresentar ao consumidor a opção mais adequada dentre o que está disponível, para assim suprir da melhor forma a expectativa desse consumidor (TOMELIN, 2001; MENEZES; STAXHYN, 2011).

A partir do exposto, entende-se ter ficado evidenciada a importância dos agentes de viagens e também quais são as atividades desempenhadas por esses profissionais dentro das agências; também aqui se mostra as expectativas criadas em relação ao consumo de determinado produto e/ou serviço, desde a procura por uma empresa especializada até a efetivação da compra. Portanto, é necessário que o agente de viagens seja capacitado e esteja sempre atualizado para conseguir identificar as necessidades dos clientes e trabalhe da melhor forma para que estas sejam supridas.

\section{AS NOVAS NECESSIDADES DO MERCADO DE AGENCIAMENTO DE VIAGENS E TURISMO}

Nas últimas três décadas o desenvolvimento do turismo foi influenciado pelos mesmos fatos que transformaram o planeta, a globalização. Marín (2004) destaca que os fatores deste processo que mais influenciam o turismo podem ser a mudança no perfil dos clientes e o aumento da concorrência e demanda, por exemplo; já no que diz respeito a função desempenhada pelas agências de viagens, anterior a estas transformações entendia-se que tais empresas realizavam a mediação de serviços e produtos turísticos como parceiros e distribuidores exclusivos. Mas isto mudou!

Entre o fim do século XX e início do século XXI, houve um marco para as agências que foi o processo de desintermediação (MARÍN, 2004; MENEZES; STAXHYN, 2011), pois a partir desse momento a figura do agente de viagens passa a ser substituída por outros canais de comunicação diretos entre fornecedores e clientes finais. Os consumidores passam a ter acesso direto a tudo que envolve uma viagem, sem dependência do serviço prestado por uma agência (TOMELIN, 2001; MARÍN, 2004; 
MENEZES; STAXHYN, 2011) e, com a internet, muitos autores previam falência das agências, pois até então elas eram os únicos intermediadores (DANTAS, 2008); porém não foi isso que aconteceu e todo esse processo levou as agências e os agentes a se transformarem.

Para Marín, (2004, p. 44): “As agências são outras. Suas formas de atuar são outras", e isto explica a atuação destes profissionais mesmo após previsões que indicavam a falência de tais empresas e consequentemente a extinção de tal cargo. Dantas (2008) afirma que com passar do tempo a internet tornou-se apenas mais uma forma de intermediação e a partir deste cenário as agências se readaptaram para permanecer no mercado, inovando na forma de divulgar seus produtos e/ou serviços e, sobretudo, na forma de atender o consumidor, pois isso é que definiria efetivamente os rumos da empresa (TOMELIN, 2001). Este processo de readaptação foi denominado como reintermediação, momento em que as agências passaram a atuar baseadas na interpretação da realidade contextualizada do mercado e nos acontecimentos que transformaram a atividade (TOMELIN, 2001).

Com a internet os agentes passaram a atender um público mais crítico e exigente, que com essa tecnologia passaram a acessar muitas informações e sendo assim, foi necessário que os profissionais se especializassem e começassem a prestar um suporte e informações mais detalhadas sobre as viagens, caracterizando-se numa prestação de serviço com diferencial (STAXHYN, 2010). Atesta-se que um atendimento de qualidade é uma importante estratégia mercadológica e também um diferencial para uma empresa (DANTAS, 2008).

Diante de todos esses acontecimentos e transformações surge um novo profissional oferecendo uma nova forma de venda por meio da consultoria; esta forma de venda envolve um atendimento diferenciado do que era praticado até então e a consultoria, conforme aponta Staxhyn (2010, p. 34): "é uma forma de captar e fidelizar os clientes e manter-se no mercado de viagens, que hoje está em mutação pela consequente globalização." Ou seja, perante as constantes modificações que ainda ocorrem, o agente precisa reinventar-se para acompanhar este processo e, neste caso, o profissional passou a atuar como consultor atendendo as novas necessidades e novos requisitos que passam a ser exigidos pela função e pelos clientes. 
A autora explica ainda a diferença dos profissionais mencionando que "Um agente apenas vende um produto, já o consultor além de vender, oferece alternativas e conselhos ao seu cliente mostrando-lhe qual o melhor destino e qual a melhor maneira de realizar a viagem.” (STAXHYN, 2010, p. 34).

Desta forma, entende-se que assim como o turismo de modo geral foi transformado, estas transformações também aconteceram no agenciamento e com o agente de viagens, por isso empresa e profissional precisaram se adaptar para sustentarem-se no mercado. Acredita-se que a sociedade contemporânea valoriza e entende a importância da informação e daí a importância dos envolvidos no agenciamento de viagens mostrarem-se atualizados diante das tendências no mundo (TRIGO, 2003).

Para Menezes e Staxhyn (2011) a transformação do profissional do agenciamento de viagens até que este se configurasse um consultor só foi possível com a experiência de atuação no setor e sensibilidade para perceber estas mudanças no cenário global e por isso a consultoria demonstra um importante diferencial competitivo no mercado do agenciamento de viagens. Sobre consultoria, Block (1991 p. 1) afirma que "Quando você não tem controle direto sobre pessoas e mesmo assim quer que elas ouçam o que você diz e prestem atenção a seus conselhos, você está diante de um dilema do consultor" e por isso no agenciamento de viagens o profissional precisa configurar-se como tal, porque não vai simplesmente vender, mas sim entender os desejos do cliente e com isso apresentar-lhe da melhor forma, as melhores opções.

Assim, percebe-se que apesar do surgimento de novas tecnologias e sobretudo o advento da internet, ainda há quem opte pela colaboração de um profissional para tal processo e daí a necessidade de transformação deste agente de viagens (que antes apenas preocupava-se em comercializar os produtos turísticos) em um efetivo consultor de viagens. Este profissional precisa ir além da venda de serviços e/ou produtos, conforme mencionado anteriormente, ele precisa ter um diferencial para cativar o cliente e para se manter no mercado que torna-se cada vez mais concorrido.

Como o consumidor passou a ter a opção de realizar suas viagens independentemente da prestação de serviço do profissional, é necessário que este cliente veja as vantagens e o valor no trabalho deste profissional, pois conforme aponta Block (1991, p. 4): “O objetivo do consultor é envolver-se em intervenções bem-sucedidas”. 
Assim sendo, para realizar um bom trabalho percebe-se que é necessário que o consultor tenha um conjunto de habilidades, sendo: habilidade técnica, que diz respeito a especialização na área; habilidades interpessoais, tais como capacidade de ouvir, apoiar, transformar ideias em palavras e até discordar de forma razoável quando for necessário; habilidades de consultoria para seguir as etapas necessárias que o processo envolve, ou seja, o contato com o cliente; além disso também é necessária a realização de diagnostico; feedback; implementação e por fim a conclusão a negociação, conforme destacam Block (1991) e Tomelin (2001).

De acordo com Block (1991) para prestação de consultoria de qualidade é necessária concentração intensa em relação a dois processos: autenticidade e atendimento direto, pois assim o consumidor sente mais confiança no que está lhe sendo oferecido e percebe que este profissional é realmente capacitado para atender suas necessidades.

A partir do que foi apresentado, é possível afirmar que a atuação do profissional realmente qualificado para prestar a consultoria de viagens é o que irá garantir que a agência mantenha-se no mercado, pois nota-se que o atendimento de um consultor capacitado é o diferencial que o cliente procura quando compara uma agência de viagens física a uma agência de viagens online.

Staxhyn (2010, p. 30) destaca que "O termo consultor, quando relacionado a viagens, ainda não é muito encontrado, por se tratar de uma função que está em fase de crescimento e assimilação por parte dos consumidores.”, ou do próprio profissional. Para ela, embora uma novidade:

O consultor de viagens é uma tendência para as agências que desejam conquistar e fidelizar clientes além de atrair outros potenciais consumidores. É o diferencial que um empreendimento pode oferecer para se manter ativo na competitividade existente no mercado. (STAXHYN, 2010, p. 30).

Com base no exposto, entende-se que em sua atuação o consultor apresenta diferencial por meio de um atendimento especializado e com isso Block (1991) e Menezes e Staxhyn (2011) explicam que os consultores focam na organização e planejamento, recomendando, prestando assistência ou dando conselhos sobre determinado assunto e deixam claro o que deve ser feito para que o cliente acredite na responsabilidade do profissional e sinta confiança nos direcionamentos, uma vez que os 
serviços e/ou produtos turísticos são intangíveis. Dessa forma o consultor de viagens precisa transmitir ao consumidor informações claras e atualizadas para que este cliente confie na capacidade e diferencial deste profissional.

Dito isto, considera-se ser possível afirmar que o profissional precisar ser capacitado, atualizado, atento e responsável para executar todo o processo de planejamento e organização da viagem, pois para além da plena satisfação do cliente, esta negociação ao seu fim deve gerar lucros para agência. Ou seja, o consultor de viagens tem a responsabilidade de atender com qualidade o cliente ao mesmo tempo em que deve gerar benefícios econômicos para a agência em que atua, para que esta se mantenha no mercado competitivo.

A partir do exposto, percebe-se que ser consultor implica em agregar valor tanto para a agência quanto para o cliente e apesar do lucro ser necessário para manter a agência no mercado, a função do consultor é muito mais que vender, ele precisa ter empatia e ser sensível para entender a necessidade de seu cliente, e atender essa expectativa. Com isto, constata-se que que o perfil do profissional é diferenciado, já que atender a necessidade e conseguir superar a expectativa do cliente é um dos objetivos buscados.

\section{A CENA TURÍSTiCA de CAMPO MOURÃo (PARANÁ/PR, BRASIL) E A AGÊNCIA VIAJAR FAZ BEM COMO UM DIFERENCIAL NO MERCADO COMPETITIVO}

A partir da exposição da importância do agenciamento para a promoção do turismo e do agenciamento para o fortalecimento e movimentação da atividade, nota-se que o profissional que atua frente a estes empreendimentos é rodeado de responsabilidades para melhor atender o cliente e satisfazer suas necessidades e/ou expectativas; sendo assim, nesta pesquisa se buscou verificar se os conceitos discorridos na teoria também se aplicavam na prática e, para isto, analisou-se a Agência de Viagens Viajar Faz Bem localizada no município de Campo Mourão (Paraná/PR, Brasil).

A cidade encontra-se no centro-oeste do estado do Paraná e de acordo com os dados do Instituto Brasileiro de Geografia e Estatística (IBGE) em 2016 a população era 
estimada em cerca de 93.547 habitantes distribuídos em uma área territorial de 757,875 $\mathrm{km}^{2}$ (IBGE, 2017). A economia do município é predominantemente agrícola, contudo na região em que faz parte, também é possível notar uma expressiva movimentação turística no município, principalmente no segmento de negócios e eventos (PREFEITURA MUNICIPAL DE CAMPO MOURÃO, PMCM, 2017).

Os atrativos de lazer em potencial referem-se a praças, parques, museu, teatro e eventos programados, citados apenas para exemplificar; e a estrutura turística do município é composta basicamente por hotéis, pousadas, restaurantes, empresas de transporte e agências de viagens (PMCM, 2017). Juntos, estrutura e atrativos mostram um relativo destaque turístico na região a que o município pertence.

Tendo em vista a oferta turística de Campo Mourão e aceitando que o agenciamento de viagens é um segmento importante para o fomento do turismo, esta pesquisa desenvolveu-se na Agência Viajar Faz Bem, uma empresa do ramo que atua na cidade desde o ano de 2013 e que junto de outras oito agências compõem o setor no referido município. Alguns desses empreendimentos são considerados concorrentes diretos da Viajar Faz Bem, devido ao fato de comercializam o mesmo tipo de produto e/ou serviço turístico para um mesmo tipo de público, e por isso diferenciar-se no mercado é um desafio que deve ser vencido se a agência objeto de estudo deseja destacar-se no mercado competitivo.

\subsection{TENDÊNCIAS DE MERCADO: A PRÁTICA DE CONSULTORIA DE VIAGENS NA AGÊNCIA VIAJAR FAZ BEM}

Conhecidas as principais discussões que nortearam esta pesquisa e visando obter informações sobre a prestação de serviço de consultoria de viagens na Agência de Viagens Viajar Faz Bem, realizaram-se observações no referido empreendimento, bem como entrevistas com a equipe de profissionais para compreender a percepção desta acerca da atuação no mercado de agenciamento e consultoria de viagens. Durante a observação foram levantados dados que permitiram analisar o cotidiano do empreendimento, o perfil dos clientes, os tipos de produtos e serviços oferecidos e como os colaboradores se comportavam em relação a prestação de serviço realizada. 
Constatou-se que os clientes da agência eram em sua maioria do sexo feminino e com poder aquisitivo elevado; procuravam viagens de lazer e os serviços e produtos mais adquiridos eram pacotes de viagens completos (com transporte aéreo, hospedagem, seguro viagem, serviço de receptivo). Os destinos mais buscados eram internacionais e essas viagens estavam sendo realizadas por famílias ou grupos de amigos.

$\mathrm{Na}$ ocasião da pesquisa o empreendimento contava com três profissionais, sendo a empreendedora e mais duas colaboradoras. A empreendedora possuindo graduação em Turismo e Hotelaria e, além disso, havia estagiado durante seu processo de formação em agências de viagens; uma das colaboradoras era graduada em Publicidade e Propaganda e iniciou sua atuação no agenciamento de viagens em outubro de 2015; já a outra colaboradora estava finalizando a graduação em Turismo e Meio Ambiente e iniciou sua atuação na área por meio de estágio firmado em dezembro de 2014 na referida agência.

De acordo com a empreendedora, ela e as colaboradoras buscavam informações junto às operadoras, consolidadores e demais parceiros da agência e as repassavam aos clientes e este também era o procedimento no que dizia respeito aos valores dos serviços e/ou produtos turísticos comercializados pela agência.

As entrevistas realizadas tiveram enfoque em diversas questões, tais como a qualidade no atendimento ao cliente, as exigências do mercado, o foco de atuação da agência, a compreensão do papel do agente de viagens bem como do consultor de viagens e desejo em exercer esta última como função primordial no empreendimento e qualificação profissional para atender as exigências e necessidades da demanda turística.

Durante a entrevista com a empreendedora, foi questionado quais elementos eram avaliados para a contratação de pessoal, ela apontou algumas características como carisma, agilidade de raciocínio e para aprender as atividades relativas à função e fisionomia (postura, vestimenta), pois para ela estes eram elementos essenciais para o trabalho com o público. Sobre capacitações ela apontou que surgem novas técnicas com grande frequência e, sendo assim, a agência se preocupava com a atualização e em repassar esses novos métodos aos colaboradores com objetivo de melhorar a prestação de serviço do empreendimento. 
O ponto principal durante a entrevista diz respeito aos questionamentos sobre consultoria e sobre isso a empreendedora afirmou que conhecia o serviço e o prestava na agência, contudo, somente após a venda já que alguns clientes podiam usar as informações para comprar em outro local (principalmente na internet que se mostra ser o principal concorrente do agenciamento de modo geral). Então, segundo a gestora, somente após a venda era prestada a consultoria ao cliente no que diz respeito ao local, o que levar, moeda e câmbio, temperatura, documentação, entre outras coisas. Por sua vez as colaboradoras afirmaram que já haviam ouvido sobre consultoria e entendiam que isto dizia respeito à atenção da empresa com o cliente, além de ser um atendimento personalizado sobre informações da viagem a ser realizada. Para elas, a diferença que percebiam entre um agente de viagens e um consultor de viagens é que o agente objetivava vendas, já o consultor se preocupava em estruturar a viagem desde a ideia inicial até a sua operacionalização efetiva; além de que este profissional deveria se comunicar adequadamente e eficazmente com o cliente se seus próprios fornecedores.

Em relação a diferença da atuação do consultor e do agente, a empreendedora definiu que o agente de viagens visava apenas venda, já o consultor preocupava-se do primeiro contato até o retorno do cliente; e de acordo com seus relatos, a profissional acreditava que a agência Viajar Faz Bem prestava serviço de consultoria de viagens desde a abertura do empreendimento e nisto estava seu diferencial. Quando questionadas sobre o mesmo assunto, as colaboradoras tiveram opiniões que divergiram entre si, uma delas acreditava que a agência prestava o serviço de consultoria, pois dedicava muita atenção aos clientes; já a outra acreditava que esse serviço era prestado de maneira superficial, uma vez que se dava apenas no pós-venda, ou seja, até que a negociação financeira não estivesse efetivada, as informações eram repassadas ao cliente de maneira parcial.

A unanimidade das respostas obtidas pelas entrevistadas, por sua vez, foi que existia uma constante preocupação com a melhoria na prestação de serviço pela empreendedora, refletindo assim no modo de atuação da agência pesquisada.

Sobre as estratégias utilizadas em relação aos meios de divulgação, a empreendedora apontou o Facebook como principal ferramenta e citava que já haviam sido realizadas propagandas em revista impressa e televisão, porém, a rede social era o que atingia mais pessoas. Como meio de divulgação e estratégia para atrair novos 
clientes, as colaboradoras também citaram o Facebook como principal ferramenta e também o WhatsApp, pois segundo elas, estes eram os meios mais rápidos para interagir com os clientes. Uma das colaboradoras ainda destacou o fato de que essas ferramentas não tinham custo adicional para o empreendimento e por meio deles se podia manter contato direto com seus clientes.

Sobre as formas empregadas para fidelização dos clientes já existentes e para atração de novos clientes, a empreendedora respondeu que igualmente o Facebook estava fazendo esta ponte devido ao seu alcance; para ela somando a agilidade da rede social com um atendimento de qualidade, o consumidor sentia desejo de voltar e realizar outras negociações. A empreendedora ressaltou que os novos clientes vinham por indicação de outros que já haviam consumido produtos e/ou serviços com a Agência Viajar Faz Bem e sentiram-se satisfeitos com o processo de negociação e realização das viagens. As duas colaboradoras concordaram com o posicionamento da empreendedora e ainda apontaram que a agência era um diferencial para Campo Mourão, pois tinha um cuidado e uma preocupação especial com seus clientes.

Já ao fim da entrevista, a empreendedora reafirmou que acreditava que sua agência era um diferencial em Campo Mourão, pois valorizava o cliente e prezava pelo bom atendimento e assessoria durante a viagem. Segundo ela, num prazo de 5 anos, a partir da realização da pesquisa, almejava-se o crescimento do empreendimento e esperava-se que este tivesse ainda mais credibilidade no mercado principalmente por oferecer ao cliente o diferencial de consultoria, agregado aos produtos e/ou serviços comercializados.

\section{CONSIDERAÇÕES FINAIS}

A partir do exposto ao longo desta pesquisa, atesta-se que o turismo é uma atividade que acontece em determinada localidade envolvendo visitante, visitado e fornecedores, dessa forma deve gerar benefícios a estes envolvidos e progredir de forma responsável. Junto à cadeia turística notou-se a presença das agências de viagens que são empresas que, por meio da intermediação, vendem produtos e/ou serviços turísticos 
ao consumidor final, conforme exposto por Barretto (2003); De la Torre (2003); Dias (2006) e Pakman (2014).

Segundo Dantas (2008); Marín (2004); Menezes e Staxhyn (2011); Staxhyn (2010); Trigo (2003) e Tomelin (2001), com a globalização, o turismo e as agências mudaram e, consequentemente, também mudou o profissional que atuava nestes empreendimentos; os agentes precisaram readaptar-se para atender as exigências frente às novas ferramentas disponíveis no mercado e precisaram prestar um atendimento de qualidade para manter a clientela e atrair novos consumidores, tornando-se assim consultores de viagens.

O consultor de viagens tem características e habilidades específicas e desde o primeiro contato atende o cliente com atenção para entender sua necessidade, desejo e/ou expectativa, segundo Block (1991) e Staxhyn (2010); para estes autores, o consultor auxilia em todos os processos da viagem, tais como a escolha do destino adequado para o perfil deste cliente; orçamentos; verificação da documentação exigida; acompanhamento durante a viagem; e atendimento durante a viagem e após o retorno.

Assim sendo, a pesquisa teve como objetivo verificar a possibilidade de atuação no segmento de consultoria de viagens pela Agência Viajar Faz Bem de Campo Mourão/PR e para responder a este objetivo foram realizados levantamento bibliográfico, observação in loco e realização de entrevistas.

Por meio de emparelhamento teórico-prático, percebeu-se que a agência Viajar Faz Bem ainda não estava prestando consultoria de viagens efetivamente, pois direcionava este tipo de atendimento somente após a efetivação da compra do cliente, contudo, concluiu-se que o empreendimento tinha capacidade de atuar neste segmento no futuro, pois empreendedora e colaboradoras demonstraram preocupação com atualização, capacitação, bem como com a prestação de um atendimento de qualidade. Assim, para prestar serviço de consultoria de viagens bastaria que a agência traçasse seus objetivos e realizasse um planejamento que definisse ações que deveriam ser tomadas para se chegar a tal ponto.

Entendendo que a consultoria de viagens é uma tendência do agenciamento, é necessário treinamento constante, leituras, atualizações em relação aos destinos, serviços, forma de atendimento, e realização de viagens que permitam ao profissional conhecer os produtos e serviços que vende e, percebeu-se que a agência em questão já 
estava tendo estas preocupações, bastando apenas focar ainda mais na prática efetiva da prestação do serviço de consultoria.

Sendo assim, o trabalho possibilitou compreender que a consultoria ainda precisa de mais estudos de profissionais da área, pois isto colaborará com a compreensão de quem é e como atua tal profissional frente as constantes transformações ocorrentes. Feito isto, considerou-se ter ficado clara a diferença do agente e a nova tendência que diz respeito à consultoria, bem como o potencial da Agência Viajar Faz Bem apresentar-se como um diferencial neste segmento em Campo Mourão. Neste sentido, atesta-se que a pesquisa respondeu ao objetivo inicial e poderá servir como um instrumento para a melhor qualificação da referida agência, bem como para o fomento das discussões pertinentes ao agenciamento de viagens e turismo no que diz respeito à prestação de consultoria de viagens.

\section{REFERÊNCIAS}

ACERENZA, M. Á. Administração do turismo. Bauru: Edusc, 2002.

BARRETTO, M. Manual de iniciação ao estudo do turismo. 13. ed. Campinas: Papirus, 2003.

BENI, M. C. Análise estrutural do turismo. 2. ed. São Paulo: Senac, 1998.

BLOCK, P. Consultoria o desafio da liberdade. São Paulo: Makron, 1991.

BRAGA, D. C. (Org.). Agências de viagens e turismo: práticas de mercado. Rio de Janeiro: Elsevier, 2008.

BRIDI, G. Formação e atuação do turismológo no cenário das agências de turismo: contrapondo competências. Dissertação de mestrado (Mestrado). Universidade de Caxias do Sul (UCS), 2010.2 Disponível em: $<$ https://repositorio.ucs.br/xmlui/bitstream/handle/11338/729/Dissertacao\%20Guilherm e\%20Bridi.pdf;jsessionid=F0CF51E0BB5DBED85244D422B25C1C54 sequence $=1>$. Último acesso em: 10/04/2017.

PMCM. PREFEITURA MUNICIPAL DE CAMPO MOURÃO. Site institucional. Disponível em: <http://www.campomourao.pr.gov.br/>.

Último acesso em: 10/04/2017. 
DANTAS, J. C. de S. Qualidade do atendimento nas agências de viagens: uma questão de gestão estratégica. 2. ed. São Paulo: Roca, 2008.

DE LA TORRE, F. Agências de viagens e transportes. 4. ed. São Paulo: Roca, 2003.

DENCKER, A. de F. M. Métodos e técnicas de pesquisa em turismo. 5. ed. São Paulo: Futura, 2001.

DIAS, R. Introdução ao turismo. 1. ed. São Paulo: Atlas, 2006.

IBGE. INSTITUTO BRASILEIRO DE GEOGRAFIA E ESTATÍSTICA. Site institucional. Disponível em: <http://www.ibge.gov.br>. Último acesso em: 11/04/2017.

MARÍN, A. Tecnologia da informação nas agências de viagens: em busca da produtividade e do valor agregado. São Paulo: Aleph, 2004.

MENEZES, V. de O.; STAXHYN, A. P. S. Consultor de viagens: o profissional do novo mercado turístico. Revista Turismo e Sociedade. V. 4, n. 2, p. 381-397, outubro de 2011.

MTUR. MINISTÉRIO DO TURISMO. Site institucional. Disponível em: <http://www.turismo.gov.br>. Último acesso em: 10/04/2017.

PACKMAN, E. T. Sobre as definições de turismo da OMT: uma contribuição à Historia do Pensamento Turístico. Anais do XI Seminário da ANPTUR 2014. Disponível em: <http://www.anptur.org.br/novo_portal/anais_anptur/anais_2014/arquivos/DFP/DFP1/0 34.pdf>. Último acesso em: 10/04/2017.

STAXHYN, A. P. Santos. Análise da consultoria de viagens nas agências de turismo de Ponta Grossa - Paraná. Monografia (Graduação). Universidade Estadual do Centro-Oeste, 2010.

TOMELIN, C. A. Mercado de Agências de Viagens: como competir diante das novas tecnologias.1.ed. São Paulo: Aleph, 2001.

TRIGO, L. G. G. Turismo e qualidade tendências contemporâneas. Campinas: Papirus, 2003.

Recebido em: 01-10-2016.

Aprovado em: 31-10-2016. 